\title{
NUEVOS USUARIOS DE LA EMPRESA INFORMATIVA
}

Pedro García-Alonso-Montoya1. Universidad Complutense de Madrid. España pedro.garciaalonso@gmail.com

\section{RESUMEN}

Internet ha transformado de un modo radical el mercado de la información, afectando a todos los modelos tradicionales de empresa informativa. El proceso unidireccional antiguo y sin retorno de comunicación entre usuarios y medios ha quedado cancelado y superado. El proceso no termina con la simple llegada del producto hasta el consumidor. Es necesario también escuchar su respuesta. Su oferta debe ser bidireccional y abierta, participativa e integradora entre el profesional y el consumidor. La distribución es ahora personalizada e inmediata: las barreras de entrada han desparecido, ya que el soporte y los canales son totalmente digitales, vía Web a las pantallas. La nueva empresa informativa online debe fijar su valor en el nivel de la audiencia a la que sirve, en el tiempo de visión que sus usuraos le dedican. La información ha pasado de ser un recurso escaso, a convertirse en un insoportable ruido mediático: la oferta satura la demanda. El receptor se ha convertido también en emisor, pues el que antes obedecía, ahora manda: es exigente, crítico, activo, productivo, colaborador, implicado, comentador y difusor con su propio entorno digital. Los usuarios son ahora viewsers (usuarios-espectadores), browsers (navegantes), players (jugadores desinteresados), prosumers (consumidoresproductores) y produsers (productores-usuarios). El público se ha convertido en comunicador. Ya no mandan los 'mass media' de las empresas, sino los 'social media' de las audiencias. La intertextualidad es una característica principal de nuestra cultura moderna. Lo que no está hoy en la Red, no está en el mundo: lo cognoscible es sólo lo accesible online. Toda la cultura universal ha quedado asumida por la Red de redes. La enseñanza, la investigación, la difusión, deben digitalizarse, si no quieren quedar trasnochadas. La civilización vendrá por las pantallas, como vino antes por las imprentas.

\footnotetext{
1 Autor correspondiente

Pedro García-Alonso-Montoya. Profesor de Periodismo. Universidad Complutense de Madrid (España)

Correo:pedro.garciaalonso@gmail.com
} 
PALABRAS CLAVE: Usuarios - Medios - Internet - Comunicación bidireccional Empresa informativa

\title{
NEW USERS OF MEDIA BUSINESS
}

\begin{abstract}
Internet transformed in a radical way the information market, affecting all the traditional models to organizate the information. That old way process of no return communication between users and media has been canceled and superseded. Communication process does not end with the mere arrival of the product to the consumer. It is also necessary to hear your response. Your bid must be bidirectional, open, participatory and inclusive between professionals and their public. Distribution is now personalized and immediate: no entry barriers have disappeared, because support and channels are fully online, by Web screens. New online media companies should determine their value throwgh the level of their attended audience, the viewing time given by their public. Information dwelt from being a scarce resource, becomming a media noise unbearable that saturates the supply demand. Receivers who before obeyed now command: demanders, critics, active, productive, helpful, involved, commentator and broadcaster with its own digital environment. Users are now viewsers (users-viewers), browsers (navigators), players (players disinterested), prosumers (consumers, producers) and produsers (producers and users). 'Mass media' companies do not order, but the 'social media' from the audience instead. Intertextuality is a main characteristic of our modern culture. What is not on the Web today, is not in the world. Everything is knowable and only available online. Every world culture has been assumed by the network of Internet. Teaching, research, dissemination, should be scanned, lest they become outdated. Civilization will come through the screens, as it came before by publishers.
\end{abstract}

KEY WORDS: Users - Media - Internet - Two way communication - Media Business

\section{INTRODUCCIÓN}

\subsection{Nuevos usuarios de la empresa informativa}

Con la llegada de Internet, asistimos a un cambio absolutamente radical en el mercado de la información. Ha afectado a todos los modelos tradicionales de empresa informativa. La estructura anterior ha quedado cancelada y superada. Ya no opera simplemente de un modo unidireccional y sin retorno. No se mueve exclusivamente dirigida desde el medio hasta el público. El proceso no termina con la simple llegada del producto hasta el consumidor. Es necesario también escuchar su respuesta. 
Tampoco funciona ya aquel antiguo sistema financiero sencillo de costes y gastos. $\mathrm{Ni}$ siquiera los cines pueden esquivar este nuevo modelo tecnológico digital.

El cine en 35 milímetros está camino de desaparecer dando paso al formato digital. El informe Think Tank on European Film and Film Policy afirma que la digitalización de los cines es un proceso imparable e irreversible. Las cifras son claras: en 2009, hubo 375 estrenos en formato digital, lo que representa un $75 \%$ del total. En el mundo ya existen casi 16.500 pantallas digitales, de las cuales unas 9.000 proyectan en tres dimensiones. Son muchas las ventajas de la digitalización, principalmente el aumento de la calidad de imagen, la disminución de los costes de material y transporte de las películas" (Digitalización de las pantallas cinematográficas, 11/03/2010).

Actualmente no existen barreras de entrada al negocio informativo, sea cual sea su formato. ¿A qué es debido? A que aquellos dos inmensos costes insalvables de difusión e impresión han quedado casi suprimidos por el nuevo modelo digital.

Del mismo modo, la función mediática anterior (el periodista hablaba revestido de autoridad, mientras que su público lo acataba sumisamente) ha quedado suprimida. El acceso del consumidor es ahora totalmente libre: ha desaparecido prácticamente el pago de recepción, las dificultades de acceso, la costosa red de distribución... Todo ello provocado gracias al nuevo servicio facilitado por la Red.

\section{DESARROLLO}

\subsection{Cambio de situación en el mercado}

Actualmente resulta impensable pretender que el usuario de los medios satisfaga, en todo o en parte, la financiación del producto informativo. Ese coste debe correr exclusivamente a cuenta del medio. Así lo considera todo el ciber usuario. Es muy duro, pero es muy cierto.

Tal vez fue la radio quien primero inició este nuevo modelo del 'gratis total'. Luego fue seguido a continuación por la televisión (salvo algunas aisladas excepciones) e igualmente adoptado después por la así llamada 'prensa gratuita'.

Quizá sea demasiado pedir al ciudadano -con los bolsillos algo resentidos por la crisis- que pague por leer el periódico que ahora consulta a diario gratis en Internet. Un 58\% de los ciudadanos rechaza la idea del 'pay-per- read' en Internet, según un sondeo realizado por la consultora Nielsen, en el que participaron 27.000 personas de 57países (Uno Media, 30/03/2010). 
La nueva empresa informativa online no ha hecho más que seguir su mismo ejemplo. Le duela a quien le duela, muy raro va a ser que los medios de difusión colectiva logren convencer a sus receptores, de que deban pagarles algo por el servicio que ellos les prestan. Es más bien al revés: quien presta realmente el favor, es la audiencia dedicándole su tiempo a visionarlo.

Realidades sociales tan clásicas como el quiosco, el papel, la tinta, la biblioteca, las imprentas... son cuestiones totalmente superadas. Hoy disponemos por doquier de pantallas, mensajes en chips, redes sociales y ordenadores portátiles de todo tipo y condición. Al mismo tiempo que el mundo informático, el mudo informativo ha dado un paso adelante, del que nunca podrá retroceder. Se trata de un fenómeno, tan importante o más que el paso de de la escritura manual a la imprenta, o el tránsito del dibujo a la escritura, de la prehistoria a la historia.

Los medios tienen que replantearse cuál va a ser ahora su nueva misión social, su función económica, su papel comunicativo, su razón de ser. Ya no vale la teoría del cuarto poder. Disponemos de un quinto poder que es ejercido directamente por el público, censurando y matizando las informaciones de los medios.

La prensa debe bajarse de su pedestal. Ya no puede pontificar ni dogmatizar. Su opinión es otra más del montón, que sólo el favor de su audiencia y el respaldo de sus lectores pueden darle un valor.

Es más, incluso los medios deben también cuestionarse cuál va a ser su nuevo modelo de financiación, ajeno ahora al consumidor. ¿Qué razón convincente podrá alegar el medio, para pretender cobrarle a su público? ¿Será el coste de distribución, cuando éste ya no existe? ¿O será por el pago del soporte tintado en papel, cuando el producto se vuelca todo en pantalla? ¿Tal vez alegará el sostenimiento del desplazamiento de sus corresponsales, cuando actualmente el acceso mediático a cualquier punto, por lejano que éste sea, es prácticamente inmediato?

\subsection{Otras funciones para el público}

De cobrarle al lector por su producto, ha pasado los medios a suplicarle que lo consuma gratuitamente. ¿Cómo es posible que el consumidor pretenda ahora no pagarle al medio, a cambio del producto informativo que de éste recibe? Muy sencillo. 
a) En primer lugar, porque el recurso escaso no es ahora la información, sino el público.

b) En segundo término, porque el ruido mediático es ensordecedor hoy en día: sobra oferta y falta demanda.

c) En tercer lugar, porque nadie está dispuesto a pagar usando una vía, lo mismo que puede recibir gratuitamente por otra, con sólo pulsar un clic.

d) $\mathrm{Y}$ en cuarto lugar, porque muchas veces las redes sociales informan gratuitamente y de modo aún más fiable e inmediato: el receptor se ha convertido en emisor.

Esto no supone rebajar el nivel del público. No se trata de que ahora equipare la prensa seria a la prensa amarilla. Bastante favor hace el público a los medios con aportarles su mayor contribución: la dedicación del tiempo suyo de visión, que es lo que da realmente valor a los medios, la audiencia suya que les respalda.

Los 'mass media' han terminado por descubrir que su valor fundamental consiste precisamente en su audiencia. Su público es la máxima valía que aporta y sustenta su negocio. Basta con ver el precio de su publicidad, que se corresponde con la categoría y con la cuantía de su público lector.

Pero este nuevo público no tiene nada que ver con el anterior. Ha cambiado radicalmente. Es exigente, crítico, activo, productivo, colaborador, implicado, comentador y difusor con su propio entorno digital. Estos aspectos y modelos son tareas nuevas, distintas y peculiares en su propio papel, función y sentido... De ahí que sólo con el nombre:

a) Unos hablan de viewsers (usuarios-espectadores),

b) otros de browsers (navegantes)

c) o de players (jugadores desinteresados),

d) otros prosumers (Ritzer, 2011) (consumidores-productores)

e) y finalmente otros hablan de produsers (Grinnell, 2009) (productores- usuarios).

Según los que proponen este último vocablo, la evolución del público receptor ha ido mutando sucesivamente, configurándose conforme al siguiente modelo: "consumer = Web $1.0 /$ prosumer $=$ Web $2.0 /$ produser $=$ Web 3.0". Paralela a la evolución digital, la evolución comercial ha ido también acoplándose sucesivamente a las transformaciones operadas en el mercado.

Hay quien se atreve a fijarlo de un modo aún más claro: "Consumer: Basic. Prosumer: Advanced (or "mid-grade"). Professional: Expert" (Menga, 2008). Son como las situaciones de infancia, adolescencia y madurez, aplicadas al público usuario. 
Existen igualmente unos motivos claros que hacen cambiar la consideración del público ante su nueva situación y papel. No puede el cliente, por lo tanto, ser tratado del mismo modo a como hasta ahora.

Tenemos que asumirlo, el consumidor manda; ya no es un ente aislado que recibe impactos comerciales en función de los cuales toma decisiones de compra, sino que tiene su propia voz que puede hacer oír muy fácilmente a través de los canales digitales, dirigiéndola no sólo hacia el anunciante sino hacia el resto de consumidores, sobre los que tiene, de forma agregada, una influencia brutal (Rodríguez Morano, 2011).

La voz del cliente ha ganado un peso y un valor comercial insustituibles. Su opinión y su dictamen avalan o desautorizan los mensajes publicitarios del comunicador.

\subsection{Nuevo formato para comunicarnos}

Como algunos lo califican, asistimos a una auténtica explosión del periodismo (Ramonet, 2011). La prensa escrita sufre una transformación radical. Todo el antiguo sistema mediático ha saltado por los aires, hecho añicos. Todo ha pasado al nuevo modelo y soporte online.

¿Cuál ha sido la causa? Obviamente, la razón principal no ha sido otra que el impacto técnico operado por la revolución digital, junto con el desarrollo humano espectacular operado por el público, mediante las nuevas redes sociales. La comunicación es inmediata y directa.

El surgimiento constante de páginas Web innovadoras y mejor adaptadas al nuevo entorno (Wayner, 2001), que compiten ahora con los medios tradicionales, representa toda una esperanza de democratización de la información. Cualquier ciudadano, sirviéndose de la nueva sociedad estructurada mediante redes, tiene la posibilidad inmediata de convertirse de alguna manera también en «periodista», con sólo acceder a los blogs, a Twitter o a Facebook, o con sólo comentar o reenviar la noticia.

La fuerza del usuario, del hasta ahora simple consumidor, es tanta, que hay quienes incluso prevén llegar a un «periodismo sin periodistas». Así titula su artículo: Journalism without Journalists.

No serán los enojados blogueros o los despistados periodistas ciudadanos, ni los locos chavales de YouTube o las fuerzas oscuras tras MySpace quienes decidirán el destino del periodismo. En última instancia, serán los lectores y anunciantes quienes muestren aquello por lo que desean pagar (Mayer, 2007). 
Es el caso de WikiLeaks: un ejemplo que garantiza la existencia de una vía de expresión independiente, libre de controles de los poderes mediáticos (Cerf, 2003). Los usurarios han sabido servirse de conductos que escapen a la vigilancia e intervención de los gobiernos y empresarios. Como sostiene el gran gurú Enrique Dans:

Wikileaks es un fenómeno imparable. Lo que hace es ofrecer una alternativa a lo que llamo habitualmente el eslabón débil. (...) Wikileaks busca formas digitales para que cualquier persona pueda mandar una serie de documentos y realizar una denuncia. Tiene abogados para intentar entender estos documentos. Por supuesto, hay técnicos que permiten crear y utilizar conexiones seguras. Y, muy importante, periodistas que permiten comprobar las fuentes de información de la denuncia. Con esta infraestructura se hace más fácil al eslabón débil romper la cadena de autoridad. Desde este punto de vista, Wikileaks es imparable. Si se consigue parar a esta organización, aparecerán muchas otras. Es la consecuencia de una sociedad hiperconectada" (Dans, 2010).

Las leyes de la información cambian a velocidad de vértigo mientras que al mismo tiempo aumenta también el riesgo de manipulación y manejo de la opinión pública, con falsedades y engaños infundados.

Por otra parte, algunos géneros informativos muy apreciados, como el periodismo testimonial, de reportaje directo y presencial, o el periodismo de investigación, explorando las fuentes, se hallan actualmente en claras vías de extinción. Su coste no resulta sostenible para las empresas mediáticas.

Aquél periodismo directo y testimonial, hoy ya casi imposible, era fruto y resultado de una tarea personalísima del reportero. Obedecía a una técnica de acercamiento propio e inmediato a los hechos narrados. El periodista narraba los acontecimientos, sirviéndose de una perspectiva personal e integrada. Para ello era imprescindible generar un contacto prolongado y profundo con los personajes involucrados (Luengo, 1984).

Tenía que reunir todo el material que un periodista persigue... y luego ir más allá aún. Parecía primordial estar allí cuando tenían lugar las escenas dramáticas, para captar el diálogo, los gestos, las expresiones faciales, los detalles del ambiente (Wolfe, 1976).

Sobre el periodismo de investigación, tan denostado por algunos políticos, me remito a la opinión de Paul Steiger director y presidente de ProPublica, una plataforma dedicada al reportaje de investigación, creada en 2008 y financiada estrictamente con 
donaciones. Su opinión es clara: "El periodismo de investigación es tan necesario como la cultura" (Celis, 2010).

\subsection{La nueva era de la comunicación}

Nuestro tercer milenio ha abierto otra nueva etapa en nuestra sociedad (Castells,1999), construida en base a su nuevo valor fundamental. Se trata de la comunicación totalmente libre y de la globalización omniabarcante.

Aquella vieja 'información' (Mattelart, 2002), exclusivamente unidireccional, ha dejado paso a la comunicación bidireccional, que es también retroactiva, de retorno, dialogante, con respuesta vuelta atrás hacia el emisor. Todo es difundido de inmediato, todo es alcanzable mundialmente. Las empresas han sido las primeras en experimentarlo.

La comunicación es un aspecto esencial en la vida de las diferentes organizaciones tanto de las que pertenecen al sistema productivo, como aquellas que están enmarcadas dentro del tercer sector. Resulta vital para ellas la relación que establecen, no solo con su público, sino además con su contexto inmediato. Las acciones que tome la empresa deben de tener la facultad de poder llegar al cliente, involucrarlo, crear en el la necesidad de respuesta. La comunicación ha de ser entonces, sinérgica (Torres, 2009).

Estamos ante un nuevo contexto mediático. No se trata de un simple cambio tecnológico, de un simple añadido online. El nuevo estatus rompe también con los papeles anteriores establecidos. Ya no hay unos medios activos, omniscientes, todo poderosos, frente a unas audiencias puramente pasivas. No estamos ante unos productores que emiten, frente a unos receptores que sólo reciben, pero que no aportan.

El consumidor de bienes o servicios en este siglo XXI es ahora un sujeto activo, no un mero sujeto 'receptivo' y pasivo. El destinatario final no es la llegada terminal a un último eslabón de la cadena productiva, sino más bien al contrario, ya que su 'feed back' relanza, corrige y mejora los productos, interviniendo de un modo decisivo en su configuración, producción y distribución.

El 'nuevo' poder del consumidor está vinculado al aumento de su capacidad productiva y relacional. "El creciente poder de los usuarios y potenciales consumidores para expresarse favorable o desfavorablemente sobre sus productos y servicios de forma masiva plantea nuevas oportunidades e inconvenientes" (Castella, 2010).

¿A qué responde este cambio? A que la oferta supera a la demanda, a que la audiencia del receptor es limitada, a que el ruido publicitario satura las vías de comunicación y a que el público pertenece a un mercado muy maduro y crítico. Estos son los motivos que señala Cassella: 
La saturación de medios y mensajes publicitarios a los que los públicos se ven expuestos sumado a la gran cantidad de opciones de las que hoy dispone una persona para informarse, comparar y evaluar la oferta publicitaria como así también la posibilidad de generar, publicar y compartir contenidos propios con otros usuarios (Castella, 2010).

Ya no mandan sólo los 'mass media' de las empresas: el poder lo han de compartir con los 'social media' de las audiencias, que relanzan y transforman el sistema de producción cultural, haciéndolo más transparente y maleable. Hay una total implicación de los públicos en los propios productos, que responden, aportan y colaboran e influyen definitivamente en la cadena de valor.

\subsection{El contexto mediático global}

Por otra parte, asistimos a una confluencia operada entre los diferentes medios, independientemente de sus soportes. Imagen, texto, sonido, película, todo llega al consumidor en el mismo soporte digital por su pantalla.

Todo llega dirigido hacia un único modelo de producción o de consumo. Los productos se han convertido deliberadamente en 'intertextuales' (Riffaterre, 1994, p. 782). Los usuarios se apropian de ellos, los modifican y los reelaboran. Es más, aportan al mercado digital también su producción privada que ellos mismos crean y elaboran. Como afirma algún autor: "La intertextualidad es la característica principal de la cultura contemporánea" (Elementos de análisis intertextual).

La Red se ha convertido en el gran canal donde los usuarios distribuyen de forma abierta los contenidos, propios y ajenos, creando redes sociales y de intercambio. Esto provoca una interacción total y una participación horizontal, un nuevo modelo de comunicación masivo y un gran proceso democratizador. Los propios sitios web se organizan a partir de criterios que van siendo configurados por los propios buscadores, con sus entradas y accesos a los sites.

Esto ha llegado a conceptualizar la Red, convirtiéndola en el gran foro abierto, en el nuevo espacio público accesible a todos. Internet ofrece toda suerte de vías y cauces de distribución y de correspondencia entre productores y consumidores, entre usuarios y públicos, entre audiencias y medios.

Las relaciones entre productores, distribuidores, reguladores y consumidores de contenidos están cambiando. Se da una unión entre el productor profesional y el consumidor. Se abre una nueva relación entre la industria y la audiencia, definida por la personalización de los productos y por la intervención del consumidor en su 
diseño.

Gran parte del tiempo libre lo dedicamos hoy a navegar por la Red. El nuevo consumidor asume esa iniciativa y papel, libre y desinteresadamente, como una parte esencial de su entretenimiento. Criticar los mensajes, matizar los contenidos, aportar su propia experiencia, aconsejar o recomendar otras fuentes y perspectivas, es una tarea que el consumidor se arroga, como libre ciudadano que es.

Eso genera una cultura interactiva, basada en la convergencia cultural y en la emergencia de una sabiduría participativa y social. La tarea de enriquecerla y mejorarla es enarbolada por todos los usuarios de la Red.

Es más: incluso el estilo generado por el uso de ciertos objetos o herramientas, adquiridos y servidos de una determinada forma, es todo un signo completo de distinción social.

\subsection{Un nuevo modelo de ciber saber}

Como afirma Agazzi, "la tecnología ha transformado nuestra forma de concebir la ciencia". La tecnología y la ciencia moderna están estructuralmente conectadas. Esto supone todo un cambio radical en nuestra perspectiva epistemológica. Hemos construido entero un nuevo mundo virtual, que asume y recoge completamente la vida social de los seres humanos, replicándola e incluso aumentándola.

No es pretencioso sostener que 'lo que no está hoy en la Red, no está en el mundo'. Lo cognoscible, es sólo lo accesible online. Ha cambiado el horizonte intelectual. Internet supone un influjo directo obrado sobre la manera de concebir el conocimiento humano. Como explica Agazzi:

Se puede afirmar que la tecnología es la condición generalizada para la construcción de los objetos científicos y para su conocimiento. (...) De un lado, pues, se necesitan conceptos, y de otro son precisas tecnologías capaces de poner en contacto estos conceptos con sus referentes (Agazzi, 2011).

Cuanto se ha dicho, todo lo que se ha publicado, cada una de las frases proclamadas públicamente, el arte y la ciencia, el conjunto de la cultura mundial, sea cual sea su idioma, queda hoy accesible a cualquier usuario, con sólo conectarse en la Red.

La biblioteca mundial es única, universal, inagotable y alcanza a cuanto existe (Candeira, 2001). Todo lo almacena, todo lo ofrece y se lo facilita al usuario de la Red.

La interactividad anuncia el final del control corporativo de la antigua cultura de masas. (...) El hipertexto hace que la memoria de cualquier persona se 
convierta en la memoria del resto de las personas y convierte a la red en la memoria mundial (De Kerckhove, 1999).

A medida que accedemos irreversiblemente en la nueva transformación digital, todos los sistemas cognitivos deben adoptar las nuevas reglas. La enseñanza, la investigación, la comunicación de cualquier tipo, no pueden permanecer indiferentes.

Aunque aún convivimos con los espacios 'out line' de la escritura y de la imprenta, al mismo tiempo nos distanciamos de ellos. No resulta raro escuchar lamentos agoreros de tecnófobos trasnochados que presagian el inevitable colapso de toda nuestra cultura (Piscitelli, 2002 y 2005).

La alfabetización significa hoy inevitablemente la digitalización. El advenimiento de la civilización de la pantalla es un paso inicial para cualquier comunidad que no quiera permanecer en el atraso de la cultura moderna. Resultan innegables las conexiones establecidas entre la complejidad tecnológica, la innovación comunicacional y la riqueza cultural.

\section{CONCLUSIONES}

Todos los modelos tradicionales de empresa informativa han quedado afectados por la revolución digital. Están obligados a asumir una transformación inevitable, necesaria e ineludible, especialmente con respecto a la relación con sus usuarios. Su oferta debe ser bidireccional y abierta, participativa e integradora.

Sus fundamentos se han transformado. Se da una unión entre el productor profesional y el consumidor. La distribución es ahora personalizada e inmediata. El cobro al consumidor es inviable. Las barreras de entrada han desparecido. El soporte es totalmente virtual. Los canales son digitales, vía Web a las pantallas.

La nueva empresa informativa online debe fijar su valor en el nivel de la audiencia a la que sirve, en el tiempo de visión que sus usuraos le dedican. La información ha pasado de ser un recurso escaso, a convertirse en un insoportable ruido mediático. La oferta satura la demanda.

El receptor se ha convertido también en emisor. El que antes obedecía, ahora manda. El nuevo usuario es exigente, crítico, activo, productivo, colaborador, implicado, comentador y difusor con su propio entorno digital. Los usuarios son ahora viewsers (usuarios-espectadores), browsers (navegantes), players (jugadores desinteresados), prosumers (consumidores-productores) y produsers (productores-usuarios). Con sólo acceder a los blogs, a Twitter,a Wikileaks o a Facebook, o con sólo comentar o reenviar la noticia, el público se ha convertido en comunicador. 
Nuestro tercer milenio ha abierto a la sociedad la era de la comunicación. Todo es difundido de inmediato, todo es alcanzable mundialmente. Ya no mandan los 'mass media' de las empresas, sino los 'social media' de las audiencias.

El nuevo formato convierte todo en muy fácilmente accesible. Imagen, texto, sonido, película, todo llega al consumidor en el mismo soporte digital por su pantalla. Además, los productos se han convertido plenamente en 'intertextuales': son modificables y suplantables por los usuarios. La intertextualidad es una característica principal de nuestra cultura moderna.

La tecnología es hoy una condición indispensable para el avance científico y para su conocimiento. Lo que no está hoy en la Red, no está en el mundo. Lo cognoscible, es sólo lo accesible online. Toda la cultura universal ha quedado asumida por la Red de redes. La enseñanza, la investigación, la difusión, deben digitalizarse, si no quieren quedar trasnochadas. La alfabetización significa hoy inevitablemente la digitalización. La civilización vendrá por las pantallas, como vino antes por las imprentas.

\section{REFRENCIAS}

Agazzi, E. El impacto epistemológico de la tecnología. Recuperado el 20/10/2010, de http://www.argumentos.us.es/numero1/agazzi.htm

Candeira, J. (2001). La Web como memoria organizada: el hipocampo colectivo de la red. Recuperado el 20 de octubre de 2010, de http://jamillan.com/para_can.htm

Cassella, R. H. (2010). Prosumers. Las empresas frente al nuevo poder del consumidor. Recuperado el 20 de octubre de 2010, de Prosumers. Las empresas frente al nuevo poder del consumidor | Suite101.nethttp://www.suite101.net/content/prosumerslas-empresas-frente-al-nuevo-poder-del-consumidor-a16626\#ixzz1WbAYUtjP

Castells, M. (1999). La era de la información: Economía, sociedad y cultura. México: Ed. Siglo XXI.

Celis, B. (2010). Reportaje: El futuro del periodismo. Paul Steiger. Director y Presidente de Prepublica. Recuperado el 20 de octubre de 2010, de

http:/ / www.elpais.com/articulo/domingo/periodismo/investigacion/necesario/c ultura/elppor/20101219elpdmg_4/Tes

Cerf, V. (2003). The Internet under Surveillance: obstacles to the free flow of information 
online. Reporters without borders. Recuperado el 20 de octubre de 2010, de http:// www.rsf.org/IMG/pdf/doc-2236.pdf

Dans, E. (2010). Wikileaks es un fenómeno imparable; si la cierran, aparecerán muchas más. Recuperado el 20 de octubre de 2010, de http://www.eldia.es/2010-1205/sociedad/16-Wikileaks-es-fenomeno-imparable-si- cierran-apareceran-muchas.htm

De Kerckhove, D. (1999). Inteligencias en Conexión. Hacia una sociedad de la Web. Barcelona: Gedisa.

Grinnell, C. K. (2009). From Consumer to Prosumer to Produser: Who Keeps Shifting My Paradigm? (We Do!). Recuperado el 20 de octubre de 2010, de http://publicculture.org/articles/view/21/3/from-consumer-to-prosumer-toproduser-who-keeps-shifting-my-paradigm-we-do

Luengo Danon, A. (1984). El aporte del nuevo periodismo. Comunicación y medios, 4. Recuperado el 20 de octubre de 2010, de www.uchile.cl/download.jsp?document $=49552 \&$ property

Maier, M. (2007). Journalism without Journalists: Vision or Caricature? Boston: Shorenstein Center on the Press

Mattelart, A. (2002). Historia de la sociedad de la información. Buenos Aires: Paidos.

Menga, R. (2008). The Differences between Consumer, Prosumer and Professional. Recuperado el 20 de octubre de 2010, de http://www.pcmech.com/article/thedifferences-between- consumer-prosumer-and-professional/

Piscitelli, A. (2002). Meta-Cultura: El eclipse de los medios masivos en la era de Internet. Buenos Aires: La Crujía.

Piscitelli, A. (2005). Internet, la imprenta del siglo XXI. Barcelona: Gedisa.

Ramonet, I. (2011). La explosión del periodismo de los medios de masas a la masa de medios. Madrid: Ed. Clave Intelectual.

Reyes, G. (1984). Polifonía textual. La citación en el relato literario. Madrid: Gredos.

Riffaterre, M. (1994). Intertextuality vs. Hypertextuality. New Literary History, 25.

Ritzer, G. \& Jurgenson, N. (2010). Production, Consumption, Prosumption: The Nature of Capitalism in the Age of the Digital Prosumer. Recuperado el 20 de octubre de 2010, 
de

http:// www.georgeritzer.com/docs/Production\%20Consumption\%20Prosumption. pdf

Rodríguez Morano, J. I. (2010). De consumer a prosumer. Marketing del IE Business School Instituto de Empresa de Madrid. Recuperado el 20 de octubre de 2010, de http://www.managementsociety.net/CONTENIDO_2.pdf

Torres, I. (2009). El valor de la comunicación. Dircom Social. Recuperado el 20 de octubre de 2010, de http://www.dircomsocial.com/profiles/blogs/el-valor- de-lacomunicacion

Digitalización de las pantallas cinematográficas. Recuperado el 20 de octubre de 2010, de http://www.educared.org/global/primerasnoticias/contenido?EDUCARED_SHARED_CONTENT_ID=4956003

Elementos de análisis intertextual. Recuperado el 20 de octubre de 2010, de http://cecad.xoc.uam.mx/librosenlinea/zavala/32intertextual.pdf

La prensa electrónica pasa página al gratis total. Recuperado el 20 de octubre de 2010, de http://es.finance.yahoo.com/noticias/la-prensa-electrnica-pasa- pgina-al-gratis-totaluno_fin-0de43cd64a56.html?x=0

Wayner, P. (2001). La ofensiva del software libre. Barcelona: Granica.

Wolfe, T. (1976). El nuevo periodismo. Madrid: Ed. Anagrama.

\section{Pedro García-Alonso-Montoya}

Profesor Contratado Doctor de Empresa Informativa, desde hace trece años imparte clases en la Universidad Complutense de Madrid. Allí se doctoró en 1995, siendo MBA por el Instituto de Empresa y doble doctor por la Universidad de Navarra (1990 y 1994). Profesor 22 años en diez Universidades de España, Nueva York y Suiza en Periodismo, Marketing, Comunicación Audiovisual y Ética empresarial. He dirigido diez tesis doctorales en Empresa Informativa, Documentación y Periodismo. Miembro fundador de European Business Ethics Network en España, Secretario Promotor de la Asociación de Periodistas Bloggers e investigador del Grupo Complutense de Investigación y Análisis de Internet en Periodismo. Autor de libros manuales universitarios 